\title{
Superficial basal cell carcinoma treated with $70 \%$ trichloroacetic acid applied topically: a case study
}

This article was published in the following Dove Press journal:

Clinical, Cosmetic and Investigational Dermatology

23 February 2017

Number of times this article has been viewed

\author{
Anca Chiriac ${ }^{1-3}$ \\ Piotr Brzezinski ${ }^{4}$ \\ Cosmin Moldovan ${ }^{5}$ \\ Cristian Podoleanu ${ }^{6}$ \\ Marius Florin Coros ${ }^{7}$ \\ Simona Stolnicu ${ }^{8}$ \\ 'Department of Dermatology, \\ Nicolina Medical Center, lasi, \\ 2Department of Dermatology, \\ Apollonia University, lasi, \\ ${ }^{3}$ Department of Dermatology, P. \\ Poni Research Institute, Romanian \\ Academy lasi, Romania; ${ }^{4}$ Department \\ of Dermatology, 6th Military Support \\ Unit, Utska, Poland; ${ }^{5}$ Department \\ of Histology, ${ }^{6}$ Department of \\ Cardiology, ${ }^{7}$ Department of Surgery, \\ ${ }^{8}$ Department of Pathology, University \\ of Medicine and Pharmacy of \\ Targu-Mures, Targu-Mures, Romania
}

Correspondence: Marius Florin Coros Department of Surgery, University of Medicine and Pharmacy of Tirgu Mures 38 Gheorghe Marinescu Street, Targu-Mures 540139, Romania

Tel +40 265215551

Email corosmariusI@gmail.com
Background: Basal cell carcinoma (BCC) is the most common form of skin cancer, affecting millions of people worldwide. The treatment concept for BCCs is the surgical one, but it is costly, as such, searching for alternative medical therapeutics is justified.

Aim: To highlight the efficacy of high concentration (70\%) trichloroacetic acid (TCA) as a choice therapy for low-risk BCC.

Method and patient: Authors present, for the first time, the use of a high concentration TCA applied once a week for 2 consecutive weeks with a toothpick, on a patient with BCC on the right preauricular area.

Results: On examination 4 weeks later, the lesion was not clinically and dermatoscopically evidenced.

Conclusion: High concentration TCA could be an effective and safe, non-invasive choice of therapy for low-risk BCC, easy to perform, not expensive, with good cosmetic results, especially for patients who are not likely to undergo invasive or expensive treatments.

Keywords: basal cell carcinoma, therapy, trichloroacetic acid, dermatology

\section{Introduction}

A 38-year-old man, working most of the time indoors as a teacher in a countryside school, far away from a dermatological specialized unit, was seen in consultation during the summer holiday. He described the presence of a crust with minor bleeding while shaving, on the right preauricular area, which had appeared 4 or 5 weeks before. On clinical examination, a small ulcerative $(0.75 \mathrm{~cm})$ lesion covered by a crust was noticed, and a presumptive diagnosis of basal cell carcinoma (BCC) was issued. The patient refused any surgical intervention, including biopsy, and he approved of a topical therapy, based on application of 70\% trichloroacetic acid (TCA). He was healthy, with no history of either allergy or drug intake, with a low socioeconomic status.

The $70 \%$ TCA was applied topically with a toothpick until a white frosting developed and burning sensation was reported by the patient. The burning sensation lasted for less than 10 minutes and the white frosting completely developed on a radius of $0.5 \mathrm{~cm}$ around the lesion. A second appointment was made and a new, similar topical TCA treatment was performed 1 week later. The patient described a small crusted ulceration after each application, slight pain, and pruritus. The patient was seen 4 weeks after the last application of topical treatment with no signs of dermatological lesion on the preauricular area (Figure 1). Follow-up at 6-months was recommended, no lesion was observed by clinical and dermatoscopic examination. 

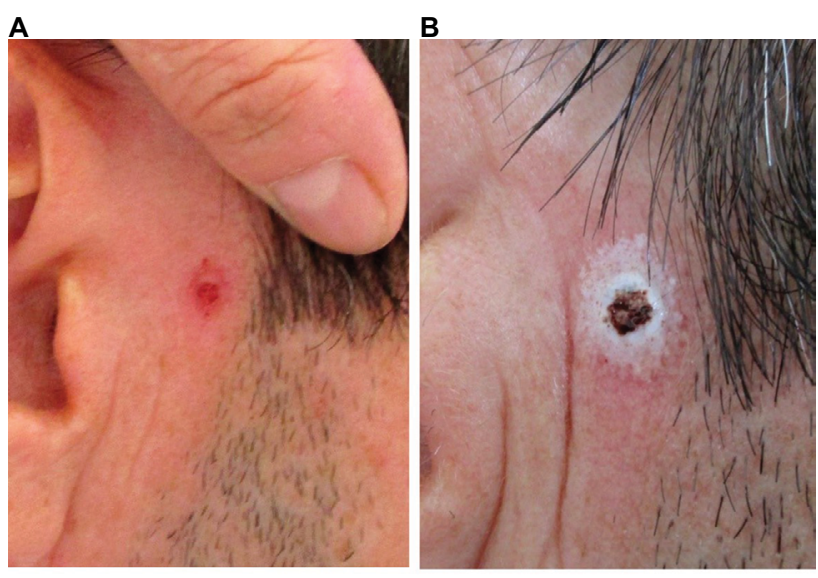

C

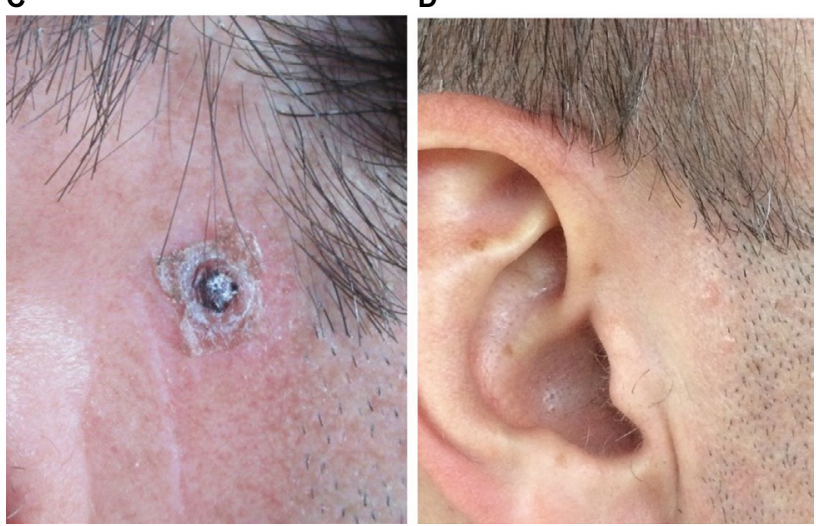

Figure I (A) A small ulcerative ulceration covered by erythematous crust; (B) first application of $70 \%$ trichloroacetic acid, frosting effect; (C) second application of $70 \%$ trichloroacetic acid; (D) no sign of dermatological lesion or tumor.

\section{Discussion}

$\mathrm{BCC}$ is the most common form of skin cancer, affecting millions of people worldwide. ${ }^{1,2}$ The originating cell belongs to pluripotential cells in the basal layer of the epidermis or follicular structures.

Treatment options for localized BCC include surgery, curettage, laser ablation, cryotherapy, topical application of imiquimod or 5-fluorouracil, photodynamic therapy, and radiotherapy. ${ }^{3}$

The preference for a treatment modality depends on variable individual factors: tumor location, size, and morphological aspect of the tumor; type of proposed therapy; modality of anesthesia; type of wound closure; risk of complications; time for healing; recurrence rate; cosmetic outcome; costs; job related issues; age and gender; the presence of comorbidities or drug intake; psychiatric illness (cancer phobia); cultural and religious dogmas; and the list could be exhaustive. An important role is played by the physician who deals with a patient diagnosed with BCC and who can persuade the patient to make the most appropriate decision for the present case and moment.
A recent study, using the data retrieved from the Danish Cancer Registry and the Danish Pathology Registry, proved that treatments were performed on a clinical diagnosis in only $21.7 \%$ of all BCC cases. ${ }^{4}$

In daily practice, in superficial small-localized BCC, clinical diagnosis is not backed by a histopathological report, due to the preference of the patients to have a quick, inexpensive, excellent cosmetic outcome in tumors located on the head and neck, with no hospitalization and no close follow-up. They value cure and cosmetic result and reassurance of immediate clinical examination in case of potential recurrence.

TCA is widely used as a peeler in cosmetics for skin rejuvenation, in treating various types of acne, including acne scars, actinic keratosis, epidermal pigmentations, and warts. ${ }^{5}$ Recent reports have been published regarding the use of TCA in different concentrations in the treatment of xanthelasma palpebrarum. ${ }^{6}$

The $70 \%$ TCA peeling is considered chemocauterization because of its caustic action (epidermal and dermal necrosis), coagulation of epidermal and dermal proteins, necrosis of collagen from upper reticular dermis and protein precipitation. ${ }^{7-9}$ The $70 \%$ TCA applied on the skin produces a "chemical burn" that will be replaced by new epidermal cells. The risk of adverse reactions is low due to the absence of systemic absorption of the TCA. ${ }^{6}$

The necrotic layers are replaced by "skin seemingly normal" due to re-epithelization from surrounding islets of keratinocytes and from skin appendages in the vicinity of the lesion.

Topical 70\% TCA applied once weekly with clinical and dermatoscopic evaluation could be an option for superficial BCC based on significant clinical efficacy, good tolerability, the least number of sessions compared to laser or cryotherapy, low-cost compared to imiquimod, and no need for anesthesia necessary for surgical excision. To the best of our knowledge, this treatment has never been published before in this type of superficial BCC in the literature.

The limitations of the method are the following: lack of histopathological control before and after the therapeutic approach, and the risk of recurrence in the absence of strict surveillance of the patients. Recurrence rate in BCC is high regardless of the treatment; even for the gold standard therapy (surgery) recurrences have been reported in $5.36 \%$ of patients after first surgical removal of the tumor, and rising to almost $50 \%$ of patients after the third or fourth operation, especially in BCC located in the periocular area. ${ }^{10}$ Recent reports indicate a recurrence rate of $1.1 \%$ per patient diagnosed with BCC after surgical removal by Mohs micrographic surgery. ${ }^{11}$ 


\section{Conclusion}

The $70 \%$ TCA could be an effective and safe non-invasive choice of therapy for low-risk BCCs; easy to perform, inexpensive, with good cosmetic results, especially for patients who are not likely to undergo invasive or expensive treatments.

\section{Contributions}

Anca Chiriac made the clinical diagnosis and treated the patient; drafted the article, revised it critically for important intellectual content; and gave final approval of the version to be published. Piotr Brzezinski made substantial contributions to the acquisition of data from the international literature and analysis and interpretation of the data; provided critical revision of the draft for important intellectual content; and gave final approval of the version to be published. Cosmin Moldovan improved the quality of the picture and translated the text; provided critical revision of the draft for important intellectual content; and gave final approval of the version to be published. Cristian Podoleanu made substantial contributions to the acquisition of data from the international literature and analysis and interpretation of the data; provided critical revision of the draft for important intellectual content; and gave final approval of the version to be published. Marius Coros prepared the document for submission; provided critical revision of the draft for important intellectual content; and gave final approval of the version to be published. Simona Stolnicu made substantial contributions to the study's conception and design and to data interpretation; drafted the article and revised it critically for important intellectual content; and gave final approval of the version to be published.

\section{Ethics and consent}

The study was approved by the Apollonia University Iasi Ethical Committee.

Written informed consent was obtained from the patient for publication of this case report and any accompanying images.

\section{Acknowledgement}

The authors thank Adrian Naznean from the Department of Foreign Languages of the University of Medicine and Pharmacy of Tîrgu Mureș for careful corrections to the manuscript.

This article was prepared or completed by the authors within their personal capacities. The opinions expressed in this article are the authors' own and do not reflect the view of the National Institutes of Health.

\section{Disclosure}

The authors declare no conflicts of interest in this work.

\section{References}

1. Gailani MR, Leffell DJ, Ziegler A, Gross EG, Brash DE, Bale AE. Relationship between sunlight exposure and a key genetic alteration in basal cell carcinoma. J Natl Cancer Inst. 1996;88(6):349-354.

2. Bellahammou K, Lakhdissi A, Akkar O, et al. Metastatic giant basal cell carcinoma: a case report. Pan Afr Med J. 2016;24:157.

3. Neville JA, Welch E, Leffell DJ. Management of non-melanoma skin cancer in 2007. Nat Clin Pract Oncol. 2007;4(8):462-469.

4. Holm AS, Nissen CV, Wulf HC. Basal cell carcinoma is as common as the sum of all other cancers: implications for treatment capacity. Acta Derm Venereol. 2016;96(4):505-409.

5. Yanofsky VR, Patel RV, Goldenberg G. Genital warts: a comprehensive review. J Clin Aesthet Dermatol. 2012;5(6):25-36.

6. Mourad B, Elgarhy LH, Ellakkawy HA, Elmahdy N. Assessment of efficacy and tolerability of different concentrations of trichloroacetic acid vs. carbon dioxide laser in treatment of xanthelasma palpebrarum. J Cosmet Dermatol. 2015;14(3):209-215.

7. Ngo AN, Ezoulin MJ, Youm I, Youan BB. Optimal concentration of 2,2,2-trichloroacetic acid for protein precipitation based on response surface methodology. J Anal Bioanal Tech. 2014;5(4):198.

8. Mradula PR, Sacchidanand S. A split-face comparative study of $70 \%$ trichloroacetic acid and $80 \%$ phenol spot peel in the treatment of freckles. J Cutan Aesthet Surg. 2012;5(4):261-265.

9. Lee JB, Chung WG, Kwahck H, Lee KH. Focal treatment of acne scars with trichloroacetic acid: chemical reconstruction of skin scars method. Dermatol Surg. 2002;28(11):1017-1021.

10. Pieh S, Kuchar A, Novak P, Kunstfeld R, Nagel G, Steinkogler FJ Long-term results after surgical basal cell carcinoma excision in the eyelid region. Br J Ophthalmol. 1999;83(1):85-88.

11. Alam M, Desai S, Nodzenski M, et al. Active ascertainment of recurrence rate after treatment of primary basal cell carcinoma (BCC). $J A m$ Acad Dermatol. 2015;73(2):323-325.
Clinical, Cosmetic and Investigational Dermatology

\section{Publish your work in this journal}

Clinical, Cosmetic and Investigational Dermatology is an international, peer-reviewed, open access, online journal that focuses on the latest clinical and experimental research in all aspects of skin disease and cosmetic interventions. This journal is included on PubMed. The manuscript management system is completely online
Dovepress

and includes a very quick and fair peer-review system, which is all easy to use. Visit http://www.dovepress.com/testimonials.php to read real quotes from published authors 